\title{
Prediction of Long-Term Canker Disease Damage from the Responses of Juvenile Poplar Clones to Inoculation with Septoria musiva
}

\author{
Jerry E. Weiland, JoAnne C. Stanosz, and Glen R. Stanosz, Department of Plant Pathology, University of Wis- \\ consin-Madison, Madison 53706-1598
}

\begin{abstract}
Weiland, J. E., Stanosz, J. C., and Stanosz, G. R. 2003. Prediction of long-term canker disease damage from the responses of juvenile poplar clones to inoculation with Septoria musiva. Plant Dis. 87:1507-1514.

Stem cankers caused by Septoria musiva severely limit production of susceptible hybrid poplars in eastern North America. A field experiment was conducted to determine whether short-term responses of poplar stems to inoculation with $S$. musiva were predictive of long-term canker disease damage. Stems of 27 poplar clones were inoculated during their first season of growth by removing the fourth or fifth fully expanded leaf and placing an agar plug colonized by an aggressive isolate of $S$. musiva over the resulting wound. Four months after inoculation, incidence of cankers, canker length, and percent of stem circumference affected (girdle) were recorded. Clones varied greatly in canker incidence (12 to 98\%), mean canker length (10 to 53 $\mathrm{mm}$ ), and mean girdle (14 to $94 \%$ ). Logistic regression analysis was used to compare these inoculation responses with canker disease damage categories assigned on the basis of information from longer-term field studies. Incidence, canker length, and girdle data were all informative, but girdle data from this field experiment correctly predicted assigned canker disease damage categories most frequently ( 24 of 27 clones). Responses of 15 of these clones also were evaluated in a similar greenhouse experiment. Although responses usually were predictive of long-term damage categories, the probability of correct prediction was lower than that obtained in the field experiment for most clones. These results demonstrate the feasibility and potential benefit of screening juvenile poplar clones for responses to inoculation with $S$. musiva before undertaking field trials for productivity and subsequent release to growers.
\end{abstract}

Populus spp. and their hybrids are among the fastest growing trees in temperate regions. Plantations of superior, vegetatively propagated poplar genotypes (clones) grown on high quality sites with management of competing vegetation have produced impressive yields $(8,17)$. Thus, interest in short-rotation intensive culture (SRIC) poplar production has accelerated with growing demands for traditional forest products and biofuels. In Oregon, Washington, and British Columbia, for example, SRIC plantations already can be important sources of fiber and lumber $(10,19,25,36)$.

Widespread adoption of SRIC poplar production in the eastern United States and Canada, however, is hindered by the occurrence of serious leafspot and canker dis-

Corresponding author: J. E. Weiland

E-mail: jew@plantpath.wisc.edu

Financial support was provided by the United States Department of Energy, the William F. Heckrodt Program for Fiber Crop Development and Utilization, the A. J. Riker Fund, the Advanced Opportunities Fellowship, and the Louis and Elsa Thomson Wisconsin Distinguished Graduate Fellowship.

Accepted for publication 15 August 2003.

Publication no. D-2003-1002-01R

(C) 2003 The American Phytopathological Society eases caused by Mycosphaerella populorum (anamorph = Septoria musiva) $(3,12,23,24,34,39)$. Leafspot reduces photosynthetic capacity of affected leaves and can cause premature defoliation. Severely cankered branches and stems are prone to breakage and can be completely girdled. Highly susceptible trees often are killed, and wood from cankered stems is of low quality and undesirable for most commercial uses.

Previous investigators have reported variation in responses of poplar clones to inoculation with S. musiva or a range in the degree of damage caused by canker diseases sometimes attributed to $S$. musiva $(3,5,6,9,12,15-18,23,34,39,40)$. Our objectives were to produce differential responses of juvenile poplar clones to inoculation with $S$. musiva and to determine whether these responses were predictive of canker disease damage previously observed for the same clones in longer-term field trials. Both a field and a greenhouse experiment tials of response data from each experiment were compared.

\section{MATERIALS AND METHODS}

Field experiment. Clonal selection, propagation, and establishment. Twentyseven poplar clones were selected to represent a range in canker disease damage in field plantings as reported in literature or were conducted, and the predictive poten- observed by authors of the present study (Table 1). Based on this information about incidence and severity of cankers, each clone was placed into one of three canker disease damage categories (low, intermediate, and high). For example, clone DN34 (assigned to our low-damage category) previously received canker disease ratings of 1.2 and 0.2 (for harsh and good sites, respectively, in the north-central United States) on a scale of 0 (low) to 3 (high) (9). This same clone also received canker disease ratings of 0.1 and 0.4 (at ages 3 and 9 years, respectively, in New York) on a 0to-3 scale (12). In contrast, clone NC11382, (assigned to our high-damage category) received canker disease ratings of 3.0 and 2.5 (for harsh and good sites, respectively) (9) and 2.8 and 1.8 (at ages 3 and 9 years, respectively) (12).

Dormant cuttings of these clones were rooted in 15-by-6-cm fiber pots (Kord Products Ltd., Brampton, Ontario, Canada), containing MetroMix 360 (The Scotts Company, Marysville, $\mathrm{OH})$ in a greenhouse in March 1998, and moved outside in April. In May, rooted cuttings were transplanted (in a completely randomized design on a spacing of 1.2 by $1.2 \mathrm{~m}$ ) into each of two plots at the University of Wisconsin-Madison West Madison Agricultural Research Station. Soil at the site is well-drained to moderately well-drained Plano silt loam that previously was planted in alfalfa. Plot 1 was planted on 9 to 10 May and plot 2 on 21 to 22 May. Bottoms of fiber pots were removed and sides were sliced with a utility knife at the time of transplanting to facilitate root emergence. Each tree was mulched with a $0.91 \times 0.91$ $\mathrm{m}$ square of perforated black plastic (Vispore tree mats; Treessentials Co., Mendota Heights, MN) and each plot was surrounded by a two-row border of clone NM6. Subsequent plot maintenance included pruning to maintain a single leader and both mechanical and chemical (glyphosate) management of competing vegetation.

Inoculation. Inoculum was produced from a single-conidial isolate of $S$. musiva (isolate 92-49A, DAOM 229444) obtained from a hybrid poplar leaf lesion. This isolate induced cankers after inoculation of poplar stems in previous studies $(15,32)$. Conidia $\left(1.7 \times 10^{6}\right.$ spores $\left./ \mathrm{ml}\right)$ stored in sterile water at $-80^{\circ} \mathrm{C}$ were streaked in three equally spaced lines on the surface of $20 \mathrm{ml}$ of malt extract agar (MEA; $10 \mathrm{~g}$ of 
malt extract, $20 \mathrm{~g}$ of agar, and 1,000 $\mathrm{ml}$ of water) in 84-mm-diameter petri dishes and allowed to grow for 2 weeks at $21^{\circ} \mathrm{C}$ under continuous fluorescent light. Plugs of inoculum ( $5 \mathrm{~mm}$ in diameter) then were cut from colony margins.

In the field experiment, up to 22 trees per clone in each plot (dependent on survival and size) were inoculated. Dates of inoculation were 22 to 23 and 28 to 29 July for plots 1 and 2, respectively. Each stem was inoculated by removing the fourth or fifth fully expanded leaf and placing a plug of inoculum on the resulting wound with the mycelium side toward the stem. The inoculum plug was held in place using a piece of plastic foam and parafilm (American National Can, Menasha, WI), as described previously $(13,15)$. Additionally, up to five trees of each clone per plot were used as controls by applying a sterile MEA plug onto the fresh wound. Plastic foam and parafilm were removed 2 weeks after inoculation and a small spot of latex paint was applied above each inoculated and control leaf scar to aid in finding the inocu- lation site during harvest. The appearance of cankers that developed in response to inoculation was noted at intervals during the growing season.

Canker evaluation. Responses of clones to inoculation in the field experiment were evaluated following harvest of plots 1 and 2 on 17 to 18 and 29 to 30 November 1998, respectively. A 30-cm-long segment of each stem, centered on the inoculation point, was collected and stored in a plastic bag at $5^{\circ} \mathrm{C}$ for up to 2 weeks, until the presence or absence of a canker on each segment was recorded. When a canker was present, the outer bark was carefully peeled away, working from healthy bark toward the inoculation point to reveal the canker margin. The length of the canker, as indicated by darkly discolored or necrotic tissue, was measured to the nearest millimeter along the stem axis. The percentage of the stem circumference affected by the canker, as indicated by darkly discolored or necrotic tissue (hereafter referred to as "girdle"), was visually estimated to the nearest $10 \%$.
Reisolation of the pathogen. Reisolation of S. musiva was attempted from 2 or 3 control trees and 10 cankered trees each of four clones (NC11004, NC11396, NC11505, and NC5262) from each plot of the field experiment (10 control and 40 inoculated trees per plot). Stem segments from plot 1 were surface disinfested by immersion for $30 \mathrm{~s}$ in $95 \%$ ethanol. Five chips of wood or bark from the margin of each canker (or the analogous location on control stems) were aseptically transferred to each of two plates containing $S$. musiva medium (SMM), an amended V8 juice agar that was developed to facilitate isolation of this fungus from poplar cankers (32). Plating of chips was completed within 2 weeks of harvest of each plot. The plates then were placed in an incubator at $21^{\circ} \mathrm{C}, 30$ $\mathrm{cm}$ below continuous fluorescent light, as described by Krupinsky (11), for 1 to 2 weeks. Stem segments from plot 2 were surface disinfested by immersion for $30 \mathrm{~s}$ in $95 \%$ ethanol, 2 min in $1.05 \%$ sodium hypochlorite solution with Tween 80 (Fisher Scientific Co., Toronto, Ontario, Canada) at

Table 1. Poplar clones, parentage, assigned canker disease damage categories, references, and responses to inoculation with Septoria musiva in a 1998 field experiment (in order of increasing severity of girdle) $)^{\mathrm{a}}$

\begin{tabular}{|c|c|c|c|c|c|c|c|c|c|c|c|c|}
\hline \multirow[b]{2}{*}{ Clone (synonyms) } & \multirow[b]{2}{*}{ Par $^{\mathbf{b}}$} & \multirow[b]{2}{*}{ Cat $^{\mathrm{c}}$} & \multirow[b]{2}{*}{$\operatorname{Ref}^{\mathrm{d}}$} & \multirow[b]{2}{*}{ Incid. $(\text { no. })^{\mathrm{e}}$} & \multicolumn{4}{|c|}{ Canker length (mm) } & \multicolumn{4}{|c|}{ Girdle (\%) } \\
\hline & & & & & Mean & No. & Range & SE & Mean & No. & Range & SE \\
\hline DTAC2 & $5 \times 2$ & Low & 12 & $28(40)$ & 10 & 11 & $6-13$ & 0.62 & 14 & 11 & $10-20$ & 1.52 \\
\hline 117.53 & $4 \times 7$ & Low & OA & $20(41)$ & 13 & 8 & $7-21$ & 1.50 & 15 & 8 & $10-30$ & 2.67 \\
\hline NC5377 (Wisconsin 5) & $4 \times 7$ & Low & $7,9,23,24$ & $23(35)$ & 10 & 7 & $4-19$ & 2.00 & 16 & 7 & $10-20$ & 2.02 \\
\hline DN74 (Stormont) & $4 \times 7$ & Low & 4,9 & $28(40)$ & 14 & 11 & $6-23$ & 1.61 & 16 & 11 & $10-30$ & 2.03 \\
\hline DN34 (NC5326, Eugenei) & $4 \times 7$ & Low & $7,9,12,23,24$ & $35(40)$ & 11 & 14 & $5-17$ & 0.99 & 17 & 14 & $10-20$ & 1.25 \\
\hline DN177 (Spijk) & $4 \times 7$ & Low & 4,9 & $52(42)$ & 13 & 22 & $4-27$ & 1.38 & 17 & 22 & $10-40$ & 1.99 \\
\hline D105 & 4 & Low & OA & $12(41)$ & 14 & 5 & $11-22$ & 1.98 & 18 & 5 & $10-20$ & 2.00 \\
\hline DN164 & $4 \times 7$ & Low & OA & $26(39)$ & 17 & 10 & $8-37$ & 2.51 & 18 & 10 & $10-30$ & 2.49 \\
\hline NC11004 (Siouxland) & $4 \times 7$ & High & 9 & $65(40)$ & 21 & 26 & $5-43$ & 1.93 & 27 & 26 & $10-50$ & 2.26 \\
\hline \multirow[t]{2}{*}{ NC5271 (NE19) } & $10 \times 9$ & Int. & $7,9,12,20$ & & & & & & & & & \\
\hline & & & $22-24,27$ & $70(40)$ & 23 & 28 & $14-37$ & 1.15 & 28 & 28 & $10-40$ & 2.12 \\
\hline NE222 & $4 \times 9$ & Int. & $9,21,27$ & $34(41)$ & 20 & 14 & $7-29$ & 1.91 & 29 & 14 & $10-50$ & 2.94 \\
\hline NE332 & $12 \times 2$ & Int. & 12 & $63(40)$ & 20 & 25 & $7-42$ & 2.06 & 29 & 25 & $10-70$ & 3.41 \\
\hline MWH20 & $4 \times 6$ & High & OA & $68(38)$ & 20 & 26 & $4-40$ & 1.53 & 31 & 26 & $10-60$ & 2.85 \\
\hline NM6 (NM104, Max 5) & $7 \times 6$ & Low & $4,9,12,34$ & $50(40)$ & 22 & 20 & $10-32$ & 1.32 & 33 & 20 & $10-60$ & 2.70 \\
\hline MWH4 & $4 \times 6$ & High & OA & $50(34)$ & 18 & 17 & $9-28$ & 1.40 & 34 & 17 & $10-70$ & 3.83 \\
\hline MWH5 & $4 \times 6$ & High & OA & $60(40)$ & 16 & 24 & $8-27$ & 0.98 & 34 & 24 & $10-70$ & 3.18 \\
\hline 13277 & 13 & High & $\mathrm{OA}$ & $41(32)$ & 19 & 13 & $10-32$ & 1.62 & 38 & 13 & $30-50$ & 2.49 \\
\hline NC5260 (Tristis 1) & $14 \times 1$ & Int. & $7,9,23$ & $48(25)$ & 24 & 12 & $11-35$ & 2.40 & 46 & 12 & $20-70$ & 4.52 \\
\hline \multirow[t]{2}{*}{ NC11432 (NC5334, NE252) } & $5 \times 13$ & High & $7,9,21,23$ & & & & & & & & & \\
\hline & & & 24,27 & $53(15)$ & 25 & 8 & $9-35$ & 2.93 & 46 & 8 & $20-70$ & 5.32 \\
\hline NC11396 (NE49) & $6 \times 2$ & High & 9,12 & 97 (39) & 26 & 38 & $6-49$ & 1.84 & 48 & 38 & $10-100$ & 3.67 \\
\hline MWH18 & $4 \times 6$ & High & $\mathrm{OA}$ & $76(38)$ & 30 & 29 & $11-50$ & 1.81 & 51 & 29 & 20-90 & 3.52 \\
\hline NE308 & $10 \times 11$ & High & $1,9,12$ & $83(40)$ & 32 & 33 & $14-50$ & 1.75 & 52 & 33 & $30-70$ & 2.06 \\
\hline NE351 & $4 \times 9$ & High & $9,24,27$ & $81(31)$ & 34 & 25 & $15-49$ & 1.70 & 57 & 25 & $20-80$ & 2.81 \\
\hline NC5331 (NE299) & $8 \times 13$ & High & $7,9,22,23,27$ & $90(41)$ & 37 & 37 & $22-51$ & 1.43 & 68 & 37 & $30-100$ & 2.91 \\
\hline \multirow[t]{2}{*}{ NC5262 (NE387) } & $3 \times 2$ & High & $7,9,20$ & & & & & & & & & \\
\hline & & & $22-24,27$ & $79(39)$ & 36 & 31 & $17-61$ & 1.78 & 72 & 31 & $30-100$ & 3.25 \\
\hline NC11382 (NE27) & $10 \times 2$ & High & 9,12 & $98(41)$ & 43 & 40 & $23-60$ & 1.22 & 74 & 40 & $40-100$ & 2.40 \\
\hline NC11505 (Kingston, NE388) & $6 \times 13$ & High & $12,13,24$ & $98(40)$ & 53 & $26^{\mathrm{f}}$ & $43-68$ & 1.01 & 94 & 39 & $70-100$ & 1.49 \\
\hline
\end{tabular}

$\bar{a}$ Trees were inoculated by removing the fourth or fifth fully expanded leaf and placing a plug of medium bearing mycelium on the resulting wound. Responses were evaluated approximately 4 months later. SE = standard error.

${ }^{\mathrm{b}}$ Parentage. Numbers refer to Populus spp. and hybrids as follows: $1=$ balsamifera, $2=$ berolinensis, $3=$ candicans, $4=$ deltoides, $5=$ deltoides var. angulata, $6=$ maximowiczii, $7=$ nigra, $8=$ nigra var. betulifolia, $9=$ nigra var. caudina, $10=$ nigra var. charkowiensis, $11=$ nigra var. incrassata, $12=$ simonii, $13=$ trichocarpa, and $14=$ tristis.

c Assigned damage category. Canker disease damage categories were assigned based on information from past field trials, as referenced in the next column; Int. = intermediate.

${ }^{\mathrm{d}}$ Numbers refer to literature cited except OA, which refers to observations by the authors of the present study of trees in clonal field trials located at Arlington, WI (unpublished)

${ }^{\mathrm{e}}$ Incidence (\%) and number in parentheses.

${ }^{\mathrm{f}}$ Due to an error, data for calculation of mean length were obtained for only 26 individuals of this clone. 
two drops per liter, and $30 \mathrm{~s}$ in $95 \%$ ethanol. Five chips from the margin of each canker then were plated onto each of two plates of SMM and also onto one plate of unamended V8 juice agar, then incubated as described above. The presence of $S$. musiva was determined on the basis of pycnidia and conidia as described by Sivanesan (28). No attempt was made to identify other organisms that grew from chips.

Greenhouse experiment. Clonal selection, propagation, and establishment. Responses of 15 of the clones used in the field experiment also were evaluated in a greenhouse experiment. Dormant cuttings were rooted in January 1999 in fiber pots as described above. Rooted cuttings were transplanted into 10-by-10-by-36-cm containers (Tall One pots; Stuewe and Sons, Inc., Corvallis, OR) 3 weeks after budbreak. The soil medium was one-half Fafard mix \#2 (Fafard, Inc, Agawam, MA) and one-half Plano silt loam from the University of Wisconsin's West Madison Agricultural Research Station. At the time of transplanting, fiber pots were sliced as described above. Half the trees of each clone were placed in a completely randomized design onto each of two greenhouse benches (plots). Natural light in the greenhouse was supplemented with 400W highpressure sodium lamps to provide a 16-h photoperiod. Maximum recorded ambient greenhouse photon flux density was 1,590 $\mu \mathrm{mol} \mathrm{s} \mathrm{m}^{-1}$ and supplemental photon flux density averaged $117 \mu \mathrm{mol} \mathrm{s} \mathrm{s}^{-1} \mathrm{~m}^{-2}$ as measured with a LI-COR photometer (model LI-189; LI-COR, Inc., Lincoln, $\mathrm{NE}$ ). The average maximum temperature was approximately $29^{\circ} \mathrm{C}$ and the average minimum temperature was approximately $16^{\circ} \mathrm{C}$. Plants were hand watered daily.

Inoculation. Inoculum was produced from $S$. musiva isolate $92-49 A$ and up to 45 trees per clone in each plot were inoculated using the procedures described for the field experiment. Dates of inoculation were 2 and 10 April for plots 1 and 2, respectively. Additionally, five trees per clone in each plot were included as controls (described above). Plastic foam and parafilm were removed 3 weeks after inoculation and a small spot of latex paint was applied above each inoculated and control leaf scar to aid in finding the inoculation site during harvest. The appearance of cankers that developed in response to inoculation was noted at intervals prior to harvest.

Canker evaluation. Responses of clones to inoculation in the greenhouse experiment were evaluated following harvest of plots 1 and 2 on 2 and 9 June 1999, respectively. A $15-\mathrm{cm}$-long segment (when possible) of each stem, centered on the inoculation point, was collected and stored in a plastic bag at $5^{\circ} \mathrm{C}$ for up to 2 weeks until presence or absence of a canker on each segment was recorded. When a canker was present, the outer bark was peeled to allow measurement of canker length and estima- tion of girdle, as described above, except that girdle was estimated to the nearest $5 \%$.

Reisolation of the pathogen. In the greenhouse experiment, reisolation of $S$. musiva was attempted from 2 or 3 control trees and 10 cankered trees of each of four clones (NC11004, NC11396, NC11505, and NC5262) from each plot (10 control and 40 inoculated trees per plot). Stem segments were surface disinfested using the procedure for plot 1 of the field experiment. Ten chips, five each from the upper and lower canker margins, were transferred aseptically to two plates containing SMM. Plating of chips was completed on the day of harvest of each plot. Plates then were incubated for 1 to 2 weeks as described above. The presence of $S$. musiva was determined on the basis of pycnidia and conidia of the pathogen. No attempt was made to identify other organisms that grew from chips.

Statistical analyses. For each experiment, data were analyzed to compare clonal responses to inoculation. Incidence data, regardless of clone, were analyzed using the $\chi^{2}$ test of independence (29) to determine if canker incidence (i.e., cankered or not cankered) was independent of plot. Severity data (length and girdle) were analyzed by two-way analysis of variance (ANOVA) for effects of clone, plot, and interaction. Girdle data were converted into proportions (percentage of stem circumference affected by canker/100) and transformed by the arcsine of the square root to homogenize variance before analyses. If plot effects were detected, subsequent analyses also were conducted using data for each plot separately. Additionally, the relationships among canker incidence, length, and girdle for each clone were examined by calculating Pearson correlation coefficients. Analyses were performed using Minitab Statistical Software (release 12.2; Minitab Inc., State College, PA).

Collected data (canker incidence, length, and girdle) also were analyzed as potential explanatory variables to determine whether they were predictive of the assigned longterm canker disease damage categories (low, intermediate, and high). These categories are viewed as ordered categorical data requiring specific methods of analysis. Thus, methods for multinomial models with ordinal responses were used (2). Such models are an extension of standard (binary) logistic regression to the case with three or more ordered categories. A key underlying assumption of these models is that of proportional odds; this assumption effectively means that there is a common slope (in the logistic regression model) separating each pair of categories. A $P$ value of less than 0.05 would indicate a failure of the proportional odds assumption (i.e., the collected data do not support the ordinal logistic model). To assess the performance of the multinomial models (given that the proportional odds assumption was met), we calculated "prediction accuracy" as the proportion of the cases (poplar clones) that were successfully predicted by the particular model. A proportion close to 1 (e.g., 24/27) suggests high model prediction accuracy. The effects of the predictor variables (incidence, length, and girdle) are quantified by a $P$ value (calculated by maximum likelihood) where each $P$ value indicates the impact of a given variable after all other terms have been accounted for. A $P$ value less than 0.05 indicates statistical significance. To test whether prediction accuracy was dependent on inclusion of clones for which long-term canker damage categories had been assigned on the basis of observations by the authors of the present study (rather than published reports), pooled mean girdle data from the field experiment also were reanalyzed with these eight clones omitted.

In the implementation of model fitting to our data, means of incidence, length, and girdle for each clone were each used as predictors in logistic regression where the outcome variable was the disease damage category. All three predictors, each possible pair of predictors, and each predictor separately were tested for each of the two experiments. Finally, data from the 15 clones common to both experiments were analyzed to allow direct comparison of the predictability of field and greenhouse experiments. Logistic regression analyses were performed using SAS (version 8; SAS Institute, Cary, NC).

\section{RESULTS}

Field experiment. Canker characteristics. Cankers were visible on the surface of some stems approximately 1 month after inoculation. Cankers that developed on inoculated trees closely resembled those attributed to natural infection of poplars by S. musiva in the field. The bark surface immediately overlying the cankers was sunken, darkly discolored greenish-brown to black, and necrotic. Bark on the face of the canker often split longitudinally. The canker margin on some of the trees was swollen due to production of callus. Cankers usually were longer than they were wide. When the outer bark was carefully removed, the canker usually extended beyond the margin visible at the bark surface. Inner bark and wood were discolored reddish-orange to black and discoloration often extended into the pith. No control trees developed cankers.

Reisolation. S. musiva was identified from $48 \%$ (19/40) of the plot 1 cankers from which reisolation was attempted. Recovery from the plot 2 cankers, which additionally had been immersed in $1.05 \%$ sodium hypochlorite and a second immersion in $95 \%$ ethanol, however, was only $15 \%(6 / 40)$. The pathogen was not isolated from control trees.

Canker incidence. Overall canker incidence was similar in each plot, with can- 
kers detected on 294 of 506 (58\%) inoculated trees in plot 1 and on 279 of 506 $(55 \%)$ inoculated trees in plot 2 . Because $\chi^{2}$ analysis indicated that incidence was independent of plot $(P=0.341)$, pooled incidence data are presented (Table 1). The clone with the least canker incidence was D105, with five cankered trees out of the 41 inoculated (12\%). Clones NC11382 and $\mathrm{NC} 11505$ had the greatest canker incidence
(98\%, or 40/41 and 39/40, respectively). Mean incidence by clone was highly correlated to mean length $(r=0.843, P<0.001)$ and mean girdle $(r=0.832, P<0.001)$ for the pooled data. Results were similar for analysis of plot 1 and 2 data separately (data not shown).

Canker length. Overall mean canker length was slightly longer in plot 1 (27.5 $\mathrm{mm})$ than in plot $2(25.5 \mathrm{~mm})$. Two-way
Table 2. Poplar clones, assigned canker disease damage categories, and probabilities of placement of respective clones in those categories as indicated by logistic regression analysis using percentage of stem circumference girdled by cankers resulting from inoculation with Septoria musiva in a 1998 field experiment ${ }^{\mathrm{a}}$

\begin{tabular}{|c|c|c|c|c|}
\hline \multirow[b]{2}{*}{ Clone } & \multirow[b]{2}{*}{ Assigned damage category ${ }^{b}$} & \multicolumn{3}{|c|}{ Probability of placement in category } \\
\hline & & Low & Intermediate & High \\
\hline DTAC2 & Low & 0.96 & 0.03 & 0.01 \\
\hline 117.53 & Low & 0.94 & 0.05 & 0.01 \\
\hline NC5377 & Low & 0.93 & 0.06 & 0.01 \\
\hline DN74 & Low & 0.91 & 0.07 & 0.02 \\
\hline DN34 & Low & 0.89 & 0.09 & 0.02 \\
\hline DN177 & Low & 0.89 & 0.09 & 0.02 \\
\hline D105 & Low & 0.86 & 0.11 & 0.02 \\
\hline DN164 & Low & 0.86 & 0.11 & 0.02 \\
\hline NC11004 & High & 0.36 & 0.42 & 0.22 \\
\hline NC5271 & Intermediate & 0.31 & 0.43 & 0.26 \\
\hline NE222 & Intermediate & 0.29 & 0.43 & 0.28 \\
\hline NE332 & Intermediate & 0.26 & 0.43 & 0.31 \\
\hline MWH20 & High & 0.18 & 0.40 & 0.41 \\
\hline NM6 & Low & 0.14 & 0.37 & 0.49 \\
\hline MWH4 & High & 0.11 & 0.33 & 0.55 \\
\hline MWH5 & High & 0.10 & 0.31 & 0.59 \\
\hline 13277 & High & 0.04 & 0.17 & 0.79 \\
\hline NC5260 & Intermediate & 0.01 & 0.04 & 0.95 \\
\hline NC11432 & High & 0.01 & 0.04 & 0.95 \\
\hline NC11396 & High & 0.00 & 0.03 & 0.97 \\
\hline MWH18 & High & 0.00 & 0.01 & 0.98 \\
\hline NE308 & High & 0.00 & 0.01 & 0.99 \\
\hline NE351 & High & 0.00 & 0.00 & 1.00 \\
\hline NC5331 & High & 0.00 & 0.00 & 1.00 \\
\hline NC5262 & High & 0.00 & 0.00 & 1.00 \\
\hline $\mathrm{NC} 11382$ & High & 0.00 & 0.00 & 1.00 \\
\hline $\mathrm{NC} 11505$ & High & 0.00 & 0.00 & 1.00 \\
\hline
\end{tabular}

${ }^{a}$ Trees were inoculated by removing the fourth or fifth fully expanded leaf and placing a plug of medium bearing mycelium over the resulting wound. Responses were evaluated approximately 4 months later.

${ }^{\mathrm{b}}$ Canker disease damage categories were assigned based on information from past field trials.

Table 3. Results of logistic regression analyses of data from responses of 27 poplar clones of three canker disease damage categories to inoculation with Septoria musiva in a 1998 field experiment ${ }^{\mathrm{a}}$

\begin{tabular}{|c|c|c|c|c|c|}
\hline \multirow[b]{2}{*}{ Predictors } & \multirow[b]{2}{*}{ Proportion $^{\mathrm{c}}$} & \multirow[b]{2}{*}{$P$ value $^{\mathrm{d}}$} & \multicolumn{3}{|c|}{ Maximum likelihood estimate $P$ value } \\
\hline & & & Incidence & Length & Girdle \\
\hline $\begin{array}{l}\text { Incidence, length, } \\
\text { girdle }\end{array}$ & $23 / 27$ & 0.2740 & 0.0720 & 0.2264 & 0.0205 \\
\hline Incidence, length & $20 / 27$ & 0.1287 & 0.0729 & 0.1691 & \\
\hline Incidence, girdle & $20 / 27$ & 0.8030 & 0.1155 & $\ldots$ & 0.0224 \\
\hline Length, girdle & $24 / 27$ & 0.1702 & & 0.8300 & 0.0208 \\
\hline Incidence & $21 / 27$ & 0.5255 & 0.0011 & & $\ldots$ \\
\hline Length & $19 / 27$ & 0.0281 & $\ldots$ & 0.0036 & \\
\hline Girdle & $24 / 27$ & 0.2802 & $\ldots$ & $\ldots$ & 0.0019 \\
\hline
\end{tabular}

a Trees were inoculated by removing the fourth or fifth fully expanded leaf and placing a plug of medium bearing mycelium over the resulting wound. Responses were evaluated approximately 4 months later.

${ }^{\mathrm{b}}$ A value of less than 0.05 indicates statistical significance (impact of a given variable after all other terms have been accounted for).

${ }^{\mathrm{c}}$ Proportion of the 27 clones tested for which the canker disease damage category predicted by responses to inoculation matched the damage category assigned based on information from past field trials.

d Proportional odds assumption $P$ value; a value of less than 0.05 indicates a failure of the proportional odds assumption (i.e., collected data do not support the ordinal logistic model).
ANOVA indicated a significant effect of clone $(P<0.001)$ and plot $(P<0.001)$ on mean canker length, but no interaction $(P=$ 0.555). The difference in length was relatively small and might be explained by the later inoculation of trees in plot 2; therefore, canker length data for both plots combined are presented in Table 1. Mean canker length varied more than fivefold between the most severely affected clone (NC11505 at $53 \mathrm{~mm}$ ) and the least-affected clones (DTAC2 and NC5377 at $10 \mathrm{~mm}$ ). Mean canker length by clone was positively correlated to mean girdle $(r=0.971$, $P<0.001)$. Results were similar for analysis of plot 1 and 2 data separately (data not shown).

Canker girdle. Overall mean girdle was $47 \%$ in plot 1 and $44 \%$ in plot 2 . Two-way ANOVA indicated a significant effect of clone on girdle $(P<0.001)$, but no effect of plot $(P=0.254)$ or interaction $(P=$ $0.271)$. Mean girdle varied, however, approximately sevenfold between the most severely affected clone (NC11505 at 94\%) and the least-affected clone (DTAC2 at $14 \%$ ) for the pooled data set (Table 1). Results were similar for analysis of plot 1 and 2 data separately (data not shown).

Prediction using field data. Results of logistic regression analyses indicated how well canker incidence, length, girdle data, or their combinations from the field experiment predicted the assigned long-term canker disease damage categories (low, intermediate, or high). For example, in the model using the pooled mean girdle data as the sole predictor, clone DN34 had a much greater probability of placement in the low damage category (probability $=0.89$ ) than in either the intermediate (probability $=$ 0.09 ) or high (probability $=0.02$ ) damage categories (Table 2). For this model, the damage category with the highest probability matched the assigned damage category for 24 of 27 clones (Tables 2 and 3) with incorrect prediction only for NC11004, NM6, and NC5260. Further, for eight of the nine clones that had been assigned to the low damage category (i.e., literature reports or our observations indicated low canker disease damage in the field), the probability of placement in the low damage category based on the field experiment girdle data alone was $\geq 0.86$ (Table 2). For 12 of the 14 clones that had been assigned to the high damage category (i.e., literature reports or our observations indicated high canker disease damage in the field), the probability of placement in the low damage category based on the field experiment canker girdle data alone was $\leq 0.11$ (Table 2 ). For this model, the corresponding proportional odds assumption $P$ value was sufficiently high $(P=0.280)$ to satisfy the assumptions for this model and the maximum likelihood estimate $P$ value was low $(P=0.002)$, indicating the significant contribution of girdle to the model after all other terms were accounted for (Table 3 ). 
None of the other models (using other variables singly or in combination) performed better than the model using girdle alone (Table 3). For example, incidence or length alone performed worse than girdle alone; neither improved predictability for a model that included girdle (Table 3). Accuracy of prediction using girdle alone was reduced only slightly when the data from plot 1 and 2 were analyzed separately (23 of 27 clones for each plot; data not shown).

Results were very similar when data were reanalyzed with omission of the eight clones for which long-term canker disease damage categories had been assigned on the basis of observation by the authors of the present study. For example, in the model using pooled mean girdle data as the sole predictor, clone DN34 had a much greater probability of placement in the low damage category (probability $=0.87$ ) than in either the intermediate (probability = 0.12 ) or high (probability $=0.01$ ) damage categories. For this model, the damage category with the highest probability matched the assigned damage category for 16 of the 19 clones. The same three clones that were incorrectly predicted using all data also were incorrectly predicted using this reduced data set. Further, for five of the six clones that had been assigned to the low damage category, the probability of placement in the low damage category based on field experiment girdle data alone was $\geq 0.87$. For eight of the nine clones that had been assigned to the high damage category, the probability of placement in the low damage category was $\leq 0.01$. For this model, the corresponding proportional odds assumption $P$ value was sufficiently high $(P=0.457)$ to satisfy assumptions for this model and the maximum likelihood estimate $P$ value was low $(P=0.005)$, indicating the significant contribution of girdle to the model after all terms were accounted for.

Greenhouse experiment. Canker characteristics. Cankers were visible on the surface of some stems as early as 3 weeks after inoculation. These initially appeared as small, elliptical, greenish-black, watersoaked lesions on the smooth green stem surfaces. As cankers developed, they often caused a constriction of affected stems. Otherwise, symptoms were similar to those described from the field experiment. No control trees developed cankers.

Reisolation. S. musiva was identified from 98\% (39/40) of the cankers from which reisolation was attempted from plot 1. Similarly, the pathogen was reisolated from $100 \%(40 / 40)$ of the cankers from plot 2. The pathogen was not isolated from control trees.

Canker incidence. Overall canker incidence was similar in each plot, with cankers detected on 299 of 350 (85\%) inoculated trees in plot 1 and 294 of $350(84 \%)$ inoculated trees in plot 2. Because $\chi^{2}$ analysis indicated that incidence was independent of plot $(P=0.599)$, pooled incidence data are presented (Table 4). The clone with the least canker incidence was 117.53, with 25 cankered trees out of the 40 inoculated (63\%). Clones NM6 and NC11396 had the greatest canker incidence (98\%, or $39 / 40$ for each). Mean incidence by clone was slightly positively correlated to mean length $(r=0.373, P=0.170)$ and mean girdle $(r=0.335, P=0.223)$ for the pooled data. Results were similar for analysis of plot 1 and 2 data separately (data not shown).

Canker length. Overall mean canker length was similar in plots 1 and 2 (30.6 and $31.0 \mathrm{~mm}$, respectively). Two-way ANOVA indicated a significant effect of clone $(P<0.001)$, but no effect of plot $(P$ $=0.203)$ or interaction $(P=0.463)$. Canker length data for both plots combined are presented in Table 4. Mean canker length varied almost fourfold between the most severely affected clone (NC11505 at 47 $\mathrm{mm}$ ) and the least severely affected clone (NM6 at $13 \mathrm{~mm}$ ). Mean length by clone was highly correlated with mean girdle $(\mathrm{r}=$ $0.920, P<0.001)$. Results were similar for analysis of plot 1 and 2 data separately (data not shown).

Canker girdle. Overall mean girdle was slightly less in plot $1(68 \%)$ than in plot 2 $(69 \%)$. Two-way ANOVA indicated a significant effect of clone on girdle $(P<$ $0.001)$ but no effect of plot $(P=0.189)$. Mean girdle varied almost fourfold between the most severely affected clone (NC5262 at 99\%) and the least-affected clone (NC5377 at 27\%) for the pooled data set (Table 4). Although a clone-plot interaction $(P=0.003)$ was detected, results were similar for most clones when data from plots 1 and 2 were analyzed separately (data not shown).

Prediction using greenhouse data. Results of logistic regression analyses indicated how well canker incidence, length, girdle data, or their combinations from the greenhouse experiment predicted the assigned long-term canker disease damage categories (low, intermediate, or high). For example, using pooled mean incidence, length, and girdle data in combination as predictors, clone DN34 had a much greater probability of placement in the low damage category (probability $=1.00$ ) than in either the intermediate (probability $=0.00$ ) or high (probability $=0.00$ ) damage categories (Table 5). For this model, the damage category with the highest probability matched the assigned damage category for 14 of 15 clones (Tables 5 and 6). However, for three of the seven clones that had been assigned to the low damage category (i.e., literature reports or our observations indicated low canker disease damage in the field), the probability of placement in the low damage category based on the greenhouse incidence, length, and girdle data in combination was $\leq 0.68$ (Table 5). For all seven clones that had been assigned to the high damage category (i.e., literature reports or our observations indicated high canker disease damage in the field), the probability of placement in the low damage category based on the greenhouse incidence, length, and girdle data used in com-

Table 4. Responses of poplar clones to inoculation with Septoria musiva in a 1999 greenhouse experiment $^{\mathrm{a}}$

\begin{tabular}{|c|c|c|c|c|c|c|c|c|c|}
\hline \multirow[b]{2}{*}{ Clone } & \multirow[b]{2}{*}{ Incidence \% (no.) } & \multicolumn{4}{|c|}{ Canker length (mm) } & \multicolumn{4}{|c|}{ Girdle (\%) } \\
\hline & & Mean & No. & Range & SE & Mean & No. & Range & SE \\
\hline DTAC2 & $73(40)$ & 22 & 29 & $7-43$ & 1.64 & 38 & 29 & $5-100$ & 3.49 \\
\hline 117.53 & $63(40)$ & 24 & 25 & $5-42$ & 2.30 & 78 & 25 & $10-100$ & 5.89 \\
\hline NC5377 & $75(40)$ & 14 & 30 & $2-27$ & 1.42 & 27 & 30 & $5-55$ & 2.73 \\
\hline DN34 & $76(90)$ & 15 & 68 & $2-34$ & 0.90 & 30 & 68 & $5-80$ & 1.84 \\
\hline DN177 & $88(40)$ & 34 & 35 & $10-46$ & 1.44 & 64 & 35 & $25-100$ & 3.65 \\
\hline D105 & $83(40)$ & 35 & 33 & $7-45$ & 1.54 & 74 & 33 & $10-100$ & 3.75 \\
\hline NC11004 & $85(40)$ & 37 & 34 & $12-54$ & 1.73 & 76 & 34 & $30-100$ & 4.49 \\
\hline NE332 & $90(40)$ & 25 & 36 & $5-40$ & 1.73 & 51 & 36 & $10-100$ & 3.55 \\
\hline NM6 & $98(40)$ & 13 & 39 & $2-27$ & 1.00 & 33 & 39 & 5-60 & 2.42 \\
\hline NC11396 & $98(40)$ & 32 & 39 & $8-49$ & 1.35 & 81 & 39 & $15-100$ & 3.96 \\
\hline NE308 & $88(40)$ & 38 & 35 & $12-53$ & 1.30 & 87 & 35 & $10-100$ & 3.69 \\
\hline NC5331 & $95(40)$ & 34 & 38 & $17-49$ & 1.18 & 86 & 38 & $15-100$ & 3.81 \\
\hline NC5262 & $93(40)$ & 42 & 37 & $32-55$ & 0.95 & 99 & 37 & $70-100$ & 0.85 \\
\hline NC11382 & $88(40)$ & 40 & 35 & $22-54$ & 1.23 & 97 & 35 & $55-100$ & 1.71 \\
\hline NC11505 & $88(90)$ & 47 & 80 & $25-60$ & 0.83 & 96 & 80 & $50-100$ & 1.34 \\
\hline
\end{tabular}

a Trees were inoculated by removing the fourth or fifth fully expanded leaf and placing a plug of medium bearing mycelium on the resulting wound. Responses were evaluated approximately 2 months later; $\mathrm{SE}=$ standard error. 
bination was $\leq 0.12$ (Table 5). For this model, the corresponding proportional odds assumption $P$ value was sufficiently high $(P=0.093)$ to satisfy the assumptions for this model (Table 6). Maximum likelinot indicate significant contribution of each of the three predictors after all other terms were accounted for (Table 6). None of the other models (using other variables singly or in combination) performed better than the model using incidence, length, and girdle data in combination (Table 6). Accuracy of prediction using incidence, length, and girdle data in combination was reduced somewhat when the plot 1 and 2 data were analyzed separately (13 of 15 clones for plot 1 and 12 of 15 clones for plot 2; data not shown).

Comparative predictability of field and greenhouse data. Comparison of the results of analysis of the data from the 15 clones common to the two experiments indicated equal or greater prediction accuracies for all models when using field data compared with greenhouse data (Table 6). Using the field data, four different models had the damage category with the highest hood estimate $P$ values for this model did

probability match the assigned damage category for 15 of 15 clones (Tables 5 and $6)$. In addition, respective proportional odds assumption $P$ values for each model were higher when field data were used compared with when greenhouse data were used. Thus, when field data were used, model assumptions were met for all models; when greenhouse data were used, model assumptions were not met for three of the seven models.

\section{DISCUSSION}

Although poplar clone breeding and selection programs have been undertaken in the eastern United States and Canada $(5,9,12,16,23,26,27,31,34)$, screening for long-term canker disease resistance by evaluating the responses of juvenile clones to inoculation with $S$. musiva is not routine. Previous reports of the artificial inoculation of young trees in the greenhouse or field studies describe canker development and variation among clones after incubation periods ranging from a few weeks to one month $(3,6,15,16,39,40)$. Differences among clones (on the basis of naturally occurring cankers that were

Table 5. Assigned poplar clone canker disease damage categories and probabilities of placement of respective clones in those categories as indicated by logistic regression analysis using incidence, length, and percentage of stem circumference girdled by cankers resulting from inoculation with Septoria musiva in a 1999 greenhouse experiment and data for the same 15 clones inoculated in a 1998 field experiment ${ }^{\mathrm{a}}$

\begin{tabular}{|c|c|c|c|c|}
\hline \multirow[b]{2}{*}{ Experiment, clone } & \multirow[b]{2}{*}{ Assigned damage category ${ }^{b}$} & \multicolumn{3}{|c|}{ Probability of placement in category } \\
\hline & & Low & Intermediate & High \\
\hline \multicolumn{5}{|l|}{ Greenhouse } \\
\hline DTAC2 & Low & 1.00 & 0.00 & 0.00 \\
\hline 117.53 & Low & 1.00 & 0.00 & 0.00 \\
\hline NC5377 & Low & 1.00 & 0.00 & 0.00 \\
\hline DN34 & Low & 1.00 & 0.00 & 0.00 \\
\hline DN177 & Low & 0.59 & 0.27 & 0.14 \\
\hline D105 & Low & 0.58 & 0.27 & 0.15 \\
\hline NC11004 & High & 0.12 & 0.24 & 0.64 \\
\hline NE332 & Intermediate & 0.83 & 0.12 & 0.05 \\
\hline NM6 & Low & 0.68 & 0.22 & 0.10 \\
\hline NC11396 & High & 0.00 & 0.00 & 1.00 \\
\hline NE308 & High & 0.00 & 0.00 & 1.00 \\
\hline NC5331 & High & 0.00 & 0.00 & 1.00 \\
\hline NC5262 & High & 0.00 & 0.00 & 1.00 \\
\hline NC11382 & High & 0.00 & 0.00 & 1.00 \\
\hline NC11505 & High & 0.00 & 0.00 & 1.00 \\
\hline \multicolumn{5}{|l|}{ Field } \\
\hline DTAC2 & Low & 1.00 & 0.00 & 0.00 \\
\hline 117.53 & Low & 1.00 & 0.00 & 0.00 \\
\hline NC5377 & Low & 1.00 & 0.00 & 0.00 \\
\hline DN34 & Low & 1.00 & 0.00 & 0.00 \\
\hline DN177 & Low & 1.00 & 0.00 & 0.00 \\
\hline D105 & Low & 1.00 & 0.00 & 0.00 \\
\hline NC11004 & High & 0.00 & 0.01 & 0.99 \\
\hline NE332 & Intermediate & 0.01 & 0.98 & 0.01 \\
\hline NM6 & Low & 1.00 & 0.00 & 0.00 \\
\hline NC11396 & High & 0.00 & 0.00 & 1.00 \\
\hline NE308 & High & 0.00 & 0.00 & 1.00 \\
\hline NC5331 & High & 0.00 & 0.00 & 1.00 \\
\hline NC5262 & High & 0.00 & 0.00 & 1.00 \\
\hline NC11382 & High & 0.00 & 0.00 & 1.00 \\
\hline NC11505 & High & 0.00 & 0.00 & 1.00 \\
\hline
\end{tabular}

$\bar{a}$ Trees were inoculated by removing the fourth or fifth fully expanded leaf and placing a plug of medium bearing mycelium over the resulting wound. Responses for greenhouse and field experiments were evaluated 2 or 4 months later, respectively.

${ }^{\mathrm{b}}$ Canker disease damage categories were based on information from past field trials. sometimes attributed to $S$. musiva) in longer-term field trials also have been reported by many authors $(5,9,12,17,18$, $23,34)$, but the cause or causes of these cankers often has not been confirmed. Limited information in the literature does suggest, however, that examination of responses of juvenile poplars might be useful in predicting longer-term performance. In as early as 1939 , Bier (3) inoculated young trees of several poplar species or hybrids with $S$. musiva in a greenhouse, and noted minimal canker development on clones that were damaged infrequently in the field compared with expanding and girdling cankers on clones known to be severely damaged in the field. Lo et al. (12), while not attributing canker damage in a clonal field trial to a particular pathogen, were able to show the positive correlation between canker damage ratings assigned to 3-year-old trees with those of the same clones rated at the age of 9 years. In the current studies, inoculation of juvenile trees with an aggressive isolate of $S$. musiva resulted in quantitatively differential responses among a variety of poplar clones. Using logistic regression, a relationship was demonstrated between this quantitative incidence and severity data and longer-term canker disease damage (regardless of potential causal agent) that was reported previously from numerous studies over a wide geographic area. Our results indicate the potential to screen poplar clones for longer-term canker disease damage by evaluating responses to artificial inoculation with $S$. musiva in one growing season in the field prior to largescale testing and release to growers.

The artificial inoculation method used in these experiments did not appear to interfere with achievement of our objectives. Although both ascospores and conidia are presumed to be essential in natural infection, extensive documentation of the relative importance of these inocula, various possible infection courts, and the timing of infection leading to cankers in nature is scarce $(3,6,14,20,35,39)$. Thus, previous researchers also have relied on similar artificial methods to induce Septoria cankers on poplars $(6,13,15,16,31,39)$. Provision of wounds, however, may allow the pathogen to bypass resistance mechanisms that operate during prepenetration, penetration, or establishment in a host and result in greater incidence or more severe disease than would be observed under natural conditions. For example, NM6 appeared somewhat susceptible in our experiments, despite its apparently low incidence and severity of canker disease in the field. In general, however, our inoculation of fresh leaf scars with $S$. musiva mycelium on agar plugs led to reproducible, widely differential responses of clones in canker incidence, length, and girdle. The predictive ability of these responses suggests that some factors important in minimizing 
long-term canker disease damage in the field were expressed in spite of the artificiality of the inoculation method.

The potential range of responses of any poplar clone to natural populations of $S$. musiva for many years could limit extrapolation from a short-term assay in which only one isolate of the pathogen is used. Although variation within $S$. musiva in color, morphology, growth rate, sporulation in culture $(33,35,37)$, isozymes (30), and random amplified polymorphic DNA markers $(37,38)$ has been described, such differences have not been related to aggressiveness. Variation in aggressiveness of isolates used in inoculation trials, however, has been reported by several researchers $(11,15,33)$. Krupinsky (11) identified differences in the severity of leaf disease produced by isolates among both location and regional collections. Although he urged the use of the most aggressive isolates in screening for disease resistance, Krupinsky noted that the full range of aggressiveness was found within local collections and he did not find good evidence for clone-isolate interaction or specificity. Variation in aggressiveness within $S$. musiva in terms of canker incidence and severity also has been reported $(15,16,33)$. Like Krupinsky, Strobl (33) found that, while isolates varied in aggressiveness in terms of canker disease, poplar clones were ranked in the same order of increasing susceptibility regardless of the isolate used. She concluded that, as long as standard clones were included, resistance among test clones could be determined. Caution dictates, however, that despite the findings of Krupinsky and Strobl and the prediction accuracy achieved in the current study, further poplar clone breeding, selection, and screening efforts should be supported by additional study of variation in $S$. musiva. More information is needed about local and regional population structures and possible clone-isolate interactions among broader collections of hosts and pathogens, and the potential for emergence of more aggressive strains.

Differences in results obtained in the field and greenhouse studies, however, do reinforce previous indications of the importance of environmental influences on host condition in Septoria canker development. In field evaluations, variation in incidence and severity of poplar cankers attributed to $S$. musiva has been related to site quality $(1,9)$. For example, Hansen et al. (9) reported that clone NC5331 (NE299) received a canker disease rating (on a scale of 0 to 3 , where $0=$ no canker and $3=$ stem dieback and breakage associated with cankers) ranging from 1.8 on good sites to 3.0 on harsh sites. Further, Maxwell et al. (15) experimentally demonstrated the influence of host stress on Septoria canker severity. Drought-stressed poplars in a greenhouse experiment developed larger cankers than well-watered trees. Similarly, despite the shorter duration of our greenhouse experiment compared with the field experiment, both incidence and severity of cankers tended to be greater in the former. Overall, there was much less variation in canker incidence among clones in the greenhouse than in the field. This suggests that differentiation between resistant and susceptible clones may be more difficult when the disease assay is conducted under greenhouse conditions. Although conditions provided in the greenhouse appeared to be adequate for good growth of the trees, lower light availability, restricted root volume, or other environmental factors may have produced conditions that enhanced infection and canker expansion.

Results of logistic regression analysis suggest that reliable prediction of longterm canker disease damage from responses to inoculation with $S$. musiva is most likely for clones at the extremes in field performance. In other words, inoculated clones that, on average, developed relatively many and large cankers or relatively few and small cankers were those that had been assigned to the high or low canker damage categories, respectively. Probabilities of placement of clones into these damage categories based on responses to inoculation were relatively high. In contrast, clones assigned to the intermediate canker damage category based on reports or observations had relatively lower probability of placement into this category based on response to inoculation (i.e., the responses to inoculation had less predictive value). No clone included in this study assigned to the intermediate or high damage category, however, had a high probability of being placed in the low damage category based on responses to inoculation. Thus, utility of these methods in screening a group of potential clones might be to identify those least likely to exhibit high incidence or severity of canker disease damage for further field testing and evaluation.

Continuing efforts to compare performance of poplar clones in field studies and to relate responses to inoculation with $S$. musiva to longer-term canker disease damage would benefit by standardization of methods. We were forced to place clones into three broad canker disease damage categories because, in past studies, canker disease rating methods have varied widely and were not always comparable. For example, Lo et al. (12) used a 0-to-3 scale to indicate incidence and severity of cankers. Strobl and Fraser (34) used incidence and a four-part categorical rating to rank clones with regard to severity, and other investigators have used location of cankers (branch or stem), incidence, and severity to rank clones $(7,9,21,23,24)$. In evaluating field performance, we favor incorporation of an indication of main stem canker incidence and severity that would relate to potential or already realized economic damage. Thus, the scale used by Lo et al. (12) in which the highest rating of 3 is assigned whenever $50 \%$ or more of the main stem is

Table 6. Results of logistic regression analyses of data from responses of 15 poplar clones of three canker disease damage categories to inoculation with Septoria musiva in a 1999 greenhouse experiment and data for the same 15 clones inoculated in a 1998 field experiment ${ }^{\mathrm{a}}$

\begin{tabular}{|c|c|c|c|c|c|}
\hline \multirow[b]{2}{*}{ Experiment, predictors } & \multirow[b]{2}{*}{ Matched $^{\mathrm{c}}$} & \multirow[b]{2}{*}{$P$ value $^{\text {d }}$} & \multicolumn{3}{|c|}{ Maximum likelihood estimate $P$ value } \\
\hline & & & Incidence & Length & Girdle \\
\hline \multicolumn{6}{|l|}{ Greenhouse } \\
\hline $\begin{array}{l}\text { Incidence, length, } \\
\text { girdle }\end{array}$ & $14 / 15$ & 0.0930 & 0.3625 & 0.7208 & 0.3643 \\
\hline Incidence, length & $13 / 15$ & 0.0779 & 0.1644 & 0.0715 & \\
\hline Incidence, girdle & $14 / 15$ & 0.1046 & 0.3592 & & 0.2826 \\
\hline Length, girdle & $13 / 15$ & 0.0380 & & 0.4732 & 0.2453 \\
\hline Incidence & $11 / 15$ & 0.4165 & 0.0544 & & $\ldots$ \\
\hline Length & $12 / 15$ & 0.0067 & $\ldots$ & 0.0255 & \\
\hline Girdle & $12 / 15$ & 0.0104 & $\ldots$ & $\ldots$ & 0.0321 \\
\hline \multicolumn{6}{|l|}{ Field } \\
\hline $\begin{array}{l}\text { Incidence, length, } \\
\text { girdle }\end{array}$ & $15 / 15$ & 0.9986 & 0.5540 & 0.6629 & 0.6232 \\
\hline Incidence, length & $15 / 15$ & 0.8930 & 0.8708 & 0.9849 & \\
\hline Incidence, girdle & $15 / 15$ & 0.9512 & 0.3293 & $\ldots$ & 0.4527 \\
\hline Length, girdle & $13 / 15$ & 0.0951 & $\ldots$ & 0.2589 & 0.3515 \\
\hline Incidence & $15 / 15$ & 0.6289 & 0.3474 & $\ldots$ & $\ldots$ \\
\hline Length & $13 / 15$ & 0.3321 & $\ldots$ & 0.1968 & \\
\hline Girdle & $12 / 15$ & 0.8197 & $\ldots$ & $\ldots$ & 0.0710 \\
\hline
\end{tabular}

a Trees were inoculated by removing the fourth or fifth fully expanded leaf and placing a plug of medium bearing mycelium over the resulting wound. Responses for greenhouse and field experiments were evaluated 2 and 4 months later, respectively.

${ }^{\mathrm{b}}$ A value of less than 0.05 indicates statistical significance (impact of a given variable after all other terms have been accounted for).

${ }^{\mathrm{c}}$ Proportion of the 15 clones tested for which the canker disease damage category predicted by responses to inoculation matched the damage category assigned based on information from past field trials.

d Proportional odds assumption $P$ value; a value of less than 0.05 indicates a failure of the proportional odds assumption (i.e., collected data do not support the ordinal logistic model). 
girdled by cankers seems very useful. Future attempts to relate responses to inoculation with $S$. musiva then could be evaluated on the ability to predict this degree of severity and associated likelihood of economic damage. Furthermore, prospective studies would benefit from the inclusion of resistant and susceptible clonal standards to allow comparison of incidence and severity values. Clones DN34 and NC11505, representing low and high canker disease damage categories, respectively, performed consistently in both experiments and generally bracketed the range of resistance exhibited by the other poplar clones in our study. Therefore, these two clones are likely standards for comparison to responses of new or untested clones to determine relative performance across a range of environmental conditions.

\section{ACKNOWLEDGMENTS}

We thank P. Crump and E. Nordheim for statistical assistance; and J. Calabro, A. Mason, and J. Scharm for their help in the collection, propagation, establishment, and maintenance of poplar clones used in these experiments.

\section{LITERATURE CITED}

1. Abebe, G., and Hart, J. H. 1990. The relationship of site factors to the incidence of Cytospora and Septoria cankers and poplar and willow borer in hybrid poplar plantations. U. S. Dep. Agric. For. Serv. Gen. Tech. Rep. NC-140.

2. Agresti, A. 1996. An Introduction to Categorical Data Analysis. John Wiley \& Sons, New York.

3. Bier, J. E. 1939. Septoria canker of introduced and native hybrid poplars. Can. J. Res. 17:195-204.

4. Boysen, B., and Strobl, S. 1991. A Grower's Guide to Hybrid Poplar. Ministry of Natural Resources, Peterborough, Ontario, Canada.

5. Farmer, R. E., Jr., Palmer, C. L., Anderson, H. W., Zsuffa, L., and O'Reilly, G. 1991. Nineyear outplanting test of cottonwood and hybrid poplar clones in northern Ontario. Tree Plant. Notes 42:49-51.

6. Filer, T. H., McCracken, F. I., Mohn, C. A., and Randall, W. K. 1971. Septoria canker on nursery stock of Populus deltoides. Plant Dis. Rep. 55:460-463.

7. Hansen, E., Moore, L., Netzer, D., Ostry, M., Phipps, H., and Zavitkovski, J. 1983. Establishing intensively cultured hybrid poplar plantations for fuel and fiber. U. S. Dep. Agric. For. Serv. Gen. Tech. Rep. NC-78.

8. Hansen, E. A., Netzer, D. A., and Tolsted, D. N. 1993. Guidelines for establishing poplar plantations in the north-central U.S. U. S. Dep. Agric. For. Serv. Res. Note NC-363.

9. Hansen, E. A., Ostry, M. E., Johnson, W. D., Tolsted, D. N., Netzer, D. A., Berguson, W. E., and Hall, R. B. 1994. Field performance of
Populus in short-rotation intensive culture plantations in the north-central U. S. U. S. Dep. Agric. For. Serv. Res. Paper NC-320.

10. Johnson, J. D. 2000. Hybrid poplar: an overview. Pages 15-19 in: Hybrid Poplars in the Pacific Northwest: Culture, Commerce, and Capability. K. A. Blatner, J. D. Johnson, and D. M. Baumgartner, eds. Coop. Ext. Misc. 0272, Pullman, WA.

11. Krupinsky, J. M. 1989. Variability in Septoria musiva in aggressiveness. Phytopathology 79:413-416.

12. Lo, M. H., Abrahamson, L. P., White, E. H., and Manion, P. D. 1995. Early measures of basal area and canker disease predict growth potential of some hybrid poplar clones. Can. J. For. Res. 25:1113-1118.

13. Long, R., Bowersox, T. W., and Merrill, W. 1986. Artificial inoculation of Populus hybrids with Septoria musiva. Can. J. For. Res. 16:405-407.

14. Luley, C. J., and McNabb, H. S., Jr. 1989. Ascospore production, release, germination, and infection of Populus by Mycosphaerella populorum. Phytopathology 79:1013-1018.

15. Maxwell, D. L., Kruger, E. L., and Stanosz, G. R. 1997. Effects of water stress on colonization of poplar stems and excised leaf disks by Septoria musiva. Phytopathology 87:381-388.

16. Mottet, M., Bussières, G., and Vallée, G. 1991. Test précoce pour l'évaluation de la sensibilité de peupliers hybrides au chancre septorien. For. Chron. 67:411-416.

17. Netzer, D. A., Tolsted, D. N., Ostry, M. E., Isebrands, J. G., Riemenshneider, D. E., and Ward, K. T. 2002. Growth, yield, and disease resistance of 7- to 12-year-old poplar clones in the north central United States. U. S. Dep. Agric. For. Serv. Gen. Tech. Rep. NC-229.

18. Newcombe, G., and Ostry, M. 2001. Recessive resistance to Septoria stem canker of hybrid poplar. Phytopathology 91:1081-1084.

19. Ondro, W. J. 1991. Present trends and future prospects for poplar utilization in Alberta. For. Chron. 67:271-274.

20. Ostry, M. E. 1987. Biology of Septoria musiva and Marssonina brunnea in hybrid Populus plantations and control of Septoria canker in nurseries. Eur. J. For. Pathol. 17:158-165.

21. Ostry, M. E., and Berguson, W. E. 1993. Selecting hybrid poplars to reduce disease risk may also reduce biomass yield. U. S. Dep. Agric. For. Serv. Tree Plant. Notes 44:128131.

22. Ostry, M. E., and McNabb, H. S., Jr. 1983. Diseases of intensively cultured hybrid poplars: a summary of recent research in the north central region. U. S. Dep. Agric. For. Serv. Gen. Tech. Rep. NC-91.

23. Ostry, M. E., and McNabb, H. S., Jr. 1985. Susceptibility of Populus species and hybrids to disease in the north central United States. Plant Dis. 69:755-757.

24. Ostry, M. E., Wilson, L. F., and McNabb, H. S., Jr. 1989. Impact and control of Septoria musiva on hybrid poplars. U. S. Dep. Agric. For. Serv. Gen. Tech. Rep. NC-133.
25. Rice, D. E. 2000. Fiber farm experiences-west of the Cascades, Fort James Fiber CompanyLower Columbia River Fiber Farm. Page 43 in: Hybrid Poplars in the Pacific Northwest: Culture, Commerce, and Capability. K. A. Blatner, J. D. Johnson, and D. M. Baumgartner, eds. Coop. Ext. Misc. 0272 Pullman, WA.

26. Riemenschneider, D. E., Berguson, W. E., Dickmann, D. I., Hall, R. B., Isebrands, J. G., Mohn, C. A., Stanosz, G. R., and Tuskan, G. A. 2001. Poplar breeding and testing strategies in the north-central U.S.: demonstration of potential yield and consideration of future research needs. For. Chron. 77: 245-253.

27. Schreiner, E. J. 1972. Procedure for selection of hybrid poplar clones for commercial trials in the northeastern region. Pages 108-116 in: 19th Proc. Northeastern Forest Tree Improvement Conference.

28. Sivanesan, A. 1990. Mycosphaerella populorum. C. M. I. descriptions of pathogenic fungi and bacteria. No. 988. Mycopathologia 109:57-58.

29. Sokal, R. R., and Rolhf, F. J. 1995. Biometry. W. H. Freeman, New York.

30. Spielman, L. J., and Hubbes, M. 1984. Characterization of Septoria musiva isolates from Ontario and the United States. (Abstr.) Phytopathology 74:840.

31. Spielman, L. J., Hubbes, M., and Lin, D. 1986. Septoria musiva on hybrid poplar in southern Ontario. Plant Dis. 70:968-971.

32. Stanosz, J. C., and Stanosz, G. R. 2002. A medium to enhance identification of Septoria musiva from poplar cankers. For. Pathol. 32:145-152.

33. Strobl, S. 1992. Feasibility of screening new hybrid poplar clones for resistance to Septoria canker. (Abstr.) For. Chron. 68:219.

34. Strobl, S., and Fraser, K. 1989. Incidence of Septoria canker of hybrid poplars in eastern Ontario. Can. Plant Dis. Surv. 69:109-112.

35. Thompson, G. E. 1941. Leaf-spot diseases of poplars caused by Septoria musiva and $S$. populicola. Phytopathology 31:241-254.

36. van Oosten, C. 2000. Hybrid poplar management in coastal British Columbia and northwest Washington. Pages 39-42 in: Hybrid Poplars in the Pacific Northwest: Culture, Commerce, and Capability. K. A. Blatner, J. D. Johnson, and D. M. Baumgartner, eds Coop. Ext. Misc. 0272, Pullman, WA.

37. Ward, K. T., Ostry, M. E., and Furnier, G. R. 1994. Morphological and molecular genetic variation among isolates of Septoria musiva. (Abstr.) Phytopathology 84:1145.

38. Ward, K. T., Ostry, M. E., and Furnier, G. R. 1997. Genetic variation in Septoria populicola and S. musiva. (Abstr.) Phytopathology 87:S101-S102.

39. Waterman, A. M. 1954. Septoria canker of poplars in the United States. U. S. Dep. Agric. Circ. No. 947, Washington, DC

40. Zalasky, H. 1978. Stem and leaf spot infections caused by Septoria musiva and $S$ populicola on poplar seedlings. Phytoprotection 59:43-50. 